\title{
HEIDEGGER E A CONCEPÇÃO DE "SIGNIFICAÇÃO" NA SUA TESE DE HABILITAÇÃO: ENTRE HUSSERL E DUNS SCOTUS E A GRAMMATICA SPECULATIVA ${ }^{1}$
}

\author{
Marcos Aurélio Fernandes $(\mathrm{UnB})^{2}$ \\ framarcosaurelio@hotmail.com
}

Resumo: $O$ presente artigo visa expor e comentar a teoria da significação apresentada por Heidegger na sua Tese de Habilitação (FREIBURG 1915) sobre a Grammatica Speculativa então atribuída a Duns Scotus. Heidegger, em sua interpretação, entrelaça elementos da teoria da significação presentes em Husserl e em Duns Scotus. A doutrina dos modos de significar, de inteligir e de ser, da Grammatica Speculativa, é lida a partir da análise intencional fenomenológica. Este artigo tenta expor este entrelaçamento, evidenciando as correspondências que há entre a teoria da significação de Husserl e a doutrina dos modos de significar, de inteligir e de ser na Grammatica Speculativa.

Palavras-chave: Ente lógico; significação; intencionalidade; modos de significar, de inteligir e de ser; Grammatica Speculativa.

A presente proposta de pensamento pretende expor a doutrina da significação que Heidegger apresenta na sua tese de habilitação defendida em 1915, que leva o título "Die Kategorien- und Bedeutungslehre des Duns Scotus" (A doutrina das categorias e da significação de Duns Scotus). O motivo para Heidegger ter escolhido este tema para sua tese reside no

\footnotetext{
${ }^{1}$ Recebido: 05-06-2016/Aceito: 20-06-2016/Publicado on-line: 28-08-2016.

${ }^{2}$ Marcos Aurélio Fernandes é Professor Adjunto I do Departamento de Filosofia da Universidade de Brasília, Brasília, DF, Brasil.
} 
seu interesse pelo problema das categorias, que, por sua vez, estava incluído na questão do ser inicialmente entrevista na leitura da Tese de Franz Brentano (1862) "Os múltiplos significados do ente segundo Aristóteles”. Tendo em vista tratar ulteriormente do problema das categorias, Heidegger recorre, então, à perspectiva da doutrina das significações, trabalhada por Husserl, a qual está em conexão com a doutrina das categorias, "à medida que a doutrina das significações salienta as diferentes formações categoriais a partir de 'significação em geral' e põe o fundamento para toda a ulterior elaboração dos problemas lógicos de sentido e de validade" (HEIDEGGER 1978, p. 203). Esta preocupação teorética levou Heidegger a escolher como texto fonte de sua pesquisa a "Grammatica Speculativa", considerada naquele tempo como sendo da autoria de Duns Scotus, mas que - como mais tarde Martin Grabmann pôs em evidência - era na verdade da autoria de Tomás de Erfurt (cfr. HEIDEGGER 1978, p. 265). Ao discutir sobre os princípios da doutrina da significação, Heidegger expõe a teoria do modus significandi e sua relação com o modus intelligendi e o modus essendi. Ao expor esta teoria, ele recorre constantemente à fenomenologia trazida à luz por Husserl antes de tudo nas suas Investigações Lógicas (publicadas em 1900/1901) e, também, com menos intensidade, no volume I das Ideias para uma fenomenologia pura e para uma filosofia fenomenológica (publicado em 1913). Como se dá, segundo a Tese de Habilitação de Heidegger, o entrelaçamento entre a análise intencional da significação desenvolvida por Husserl e a doutrina dos modos de significar, de inteligir e de ser da Grammatica Speculativa? Que correspondências podem ser encontradas entre ambas as perspectivas? É o que se pretende expor com este artigo. Antes, porém, de ir a este ponto, é preciso expor, a 
modo de consideração preliminar, algo sobre o ente lógico e sobre o estatuto e o modo de ser da expressão, em Husserl e em Duns Scotus.

\section{DO ENTE LÓGICO OU DE RAZÃO}

O terceiro capítulo da tese de habilitação de Heidegger se intitula Sprachgestalt und Sprachgehalt - Der Bedeutungsbereich (Forma linguística e conteúdo linguístico - o domínio da significação). Nos capítulos anteriores, Heidegger tinha demonstrado que o ens logicum, que, para ele, é o sentido (Sinn) e seus componentes, as significações (Bedeutungen), se mostra como um mundo próprio, contraposto ao ser real (realen Sein), com seus dois lados, a saber, em primeiro lugar, a existência, quer dizer, o modo de realidade (Wirklichkeitsweise), que concerne ao fato de que algo é (Dassheit), e, em segundo lugar, a essência em seu conteúdo, que indica $o$ que é algo, a sua quididade (Washeit).

Façamos apenas um aceno para este ponto de partida da doutrina da significação exposta por Heidegger, visto que uma elucidação dele demandaria uma investigação à parte, ligada com os dois primeiros capítulos da tese de habilitação, que tratam, respectivamente, de duas propriedades transcendentais do ens, a saber, o unum e o verum. Nosso aceno será dado apenas para que este ponto de partida seja minimamente considerado. A pressuposição deste ponto de partida é que o ente lógico se diferencia do ente real e a ele se contrapõe. Na linguagem da escolástica de Scotus, podese dizer que ens realis e ens rationis se distinguem e se contrapõem. Duns Scotus caracteriza o ente em sentido lógico 
como ens rationis (ente de razão), ente pensado ${ }^{3}$. Enquanto, de um lado, o ens naturae (ente de natureza), quer dizer, o ente real, físico ou psíquico, sensível ou suprassensível, corpóreo ou incorpóreo, é um ente extra animam, fora da alma (nós diríamos "transcendente" à consciência), por outro lado, o ens rationis é um ente in anima. Não que o ente de razão seja um pedaço, uma secção da realidade psíquica. $\mathrm{O}$ ens rationis é, na verdade, um ens diminutum (ente diminuto, apequenado, contraído) ${ }^{4}$. Dele Duns Scotus afirma, na Ordinatio (I, dist. XIII, q. unic. 893b sq. N. 7), que "non habet esse realis existentiae" (não tem o ser real da existência) .

Ora, também Husserl, em sua contraposição ao psicologismo, nas Investigações Lógicas, procura mostrar a diferenciação entre o lógico e o real-psíquico. Na esteira de Bolzano, Husserl defende a posição, segundo a qual o domínio daquilo que é lógico é essencialmente objetivo, há um seu próprio "in se", não dependendo, por conseguinte, da subjetividade de quem pensa ou expressa, seja um homem ou não. Diz Husserl nas Investigações Lógicas: "O que é verdadeiro, é absolutamente verdadeiro, é 'em si' verdadeiro; a verdade é idêntica e só uma, sejam homens ou não, sejam anjos ou deuses que a apreendem no juízo" (HUSSERL 2014, p. 88). O “em si” da verdade deve poder ser interpretado corretamente. Em questão aqui não está uma noção de verdade necessária em oposição à verdade contingente; nem se trata do ideal em sentido normativo; nem se trata da idealidade do ideal entendido como arquétipo concreto. A

\footnotetext{
${ }^{3}$ Cfr. Quaestiones Super Librum Elenchorum (Q. 1, n. 2): "Sed ens est duplex, scilicet, naturae, et rationis. Ens autem naturae inquantum tale, est cuius esse non dependet ab anima. Sed ens rationis dicitur de quibusdam intentionibus, quas adinventit ratio in ipsis rebus, cuiusmodi sunt Genus, Species, Definitio, et huiusmodi" (SCOTUS 1998, p. 1005-1006).

${ }^{4}$ Cfr. Quaestiones in Metaphyscia (L. VI, Q. 3, n. 72), onde Scotus designa o "ens diminutum" como "ens logicum proprie" (SCOTUS 1998, p. 303).
} 
idealidade em questão é a da unidade na multiplicidade (cfr. SCHÉRER 1969, p. 176). A verdade é, pois, uma unidade ideal, que é sempre a mesma, ainda que os atos de juízo sejam muitos e variados, e executados por vários sujeitos, diversos numericamente ou até mesmo especificamente. A idealidade da linguagem e da verdade implica que a significação não é o produto da consciência humana. Ela pertence a outro modo de ser que o da consciência .

A lógica ganha, assim, o caráter de objetividade. Já na esteira de Herbart, Husserl defende a posição, segundo a qual a lógica se ocupa do pensado (das Gedachte), isto é, do conceito em sua unidade ideal e em sua identidade permanente consigo mesmo, e não do pensamento (das Denken), entendido como processo psíquico cognitivo real, intimamente conexo a mecanismos fisiológico-cerebrais, que é tomado em consideração pela psicologia (Cfr. HUSSERL 2014, p. 160). O conceito não é nada de real, não é nem físico, nem psíquico. Não são partes dos atos psíquicos. Conceito, em sentido lógico, isto é, não psicológico, se refere ao concebido, ao pensado como tal, abstraindose do modo em que nós o pensamos, isto é, o recebemos, o produzimos e reproduzimos, pelos nossos atos reais. A lógica pura teria como objeto as relações do pensado (Verhältnisse des Gedachten), ou seja, os conteúdos de nossas representações. Estas, por sua vez, possuem o caráter essencial de idealidade, isto é, são relações ideais, onde ideal é entendido como o contrário de real. O ideal - e não o real - é o que subsiste em si mesmo de modo permanente e sempre idêntico. Somente o real está sujeito às leis do devir e da necessidade natural, física ou psíquica. O ideal não está. Assim, para dizer com Leibniz, a lógica não trata de verdades de fato (verités de fait), que tratam de objetualidades reais, mas sim de ver- 
dades de razão (verités de raison), que tratam de objetualidades ideais (cfr. HUSSERL 2014, p. 139) .

Em sua controvérsia com o psicologismo, Husserl procura mostrar como lei lógica não implica um "matter of fact”, nem mesmo a existência de representações ou juízos ou demais fenômenos do conhecimento. Nenhuma lei lógica é, segundo o seu sentido genuíno, uma lei para atividades da vida psíquica, portanto, nem para representações, isto é, as vivências do representar, nem para juízos, isto é, as vivências do julgar, nem ainda para demais vivências psíquicas (cfr. HUSSERL 2014, p. 47-49). Assim, por exemplo, contra John Stuart Mill, Husserl procura mostrar que o princípio de não contradição, enquanto lei lógica, não exprime "nenhum constrangimento psicológico, mas a intelecção de que proposições opostas não são simultaneamente verdadeiras, ou os estados de coisas correspondentes a elas não podem existir conjuntamente" (HUSSERL 2014, p. 67). As leis lógicas devem ser distinguidas das leis naturais e das leis morais. As leis lógicas não são nem regras práticas para o agir humano, nem asserções sobre regularidades aproximativas que possuem o caráter de uma probabilidade mais ou menos certa de que o estado de coisas é assim e não de outra forma. As leis lógicas oferecem uma certeza apodítica, uma certeza peremptória de uma verdade que deve ser assim e não pode não ser de outra forma. No caso do princípio de não contradição afirma Husserl: "temos evidência apodítica, i.e., intelecção no sentido pleno da palavra, em relação à inverdade conjunta de proposições contraditórias e, respectivamente, para a não existência conjunta de estados de coisas opostos. A lei desta incompatibilidade é o princípio genuíno da não contradição" (HUSSERL 2014, p. 68-69). Na verdade, para Husserl, os 
termos lógicos, quais representação, conceito, juízo, inferência, demonstração, teoria, necessidade, verdade e outros afins, podem e devem apresentar-se também como nomes de classes para vivências psíquicas e formações disposicionais. Mas os conteúdos puramente lógicos a que estes termos se referem e que entram em questão na formulação das leis da lógica não são atos nem fatos psíquicos. Os conceitos sobre os quais se constroem as leis lógicas não podem ter uma extensão empírica, ou seja, conceitos universais, cuja extensão é preenchida por singularidades fatuais, mas têm de serem conceitos gerais genuínos, cuja extensão se compõe exclusivamente de singularidades ideais, de espécies genuínas (cfr. HUSSERL 2014, p. 128) .

$\mathrm{O}$ que Duns Scotus chama de ens rationis (ente de razão), Husserl chama de sentido noemático. O ente de razão não é algo de real (real), no sentido de positivo, factual, objetivamente dado a modo de uma coisa (res), nem é algo de real (reell) no sentido da imanência da esfera da consciência e de suas vivências. Com outras palavras, ele não é uma parte do ato real de pensar, mas um correlato ideal dele. É o pensado do pensar, o seu conteúdo ou sentido noemático. Duns Scotus diz que o ens rationis não está subiective in intellectu, ou seja, que ele não está no intelecto como algo que nele subsiste, como se fosse uma "afecção da alma”. Ele está no intelecto, antes, de modo obiective, isto é, como algo que é representado pelo intelecto, ao modo de um conteúdo pensado $^{5}$. O ens rationis, assim, é tomado como puro objeto de consideração do intelecto, como um consideratum inquan-

\footnotetext{
${ }^{5}$ Cfr. Quaestiones Super Porphirium (Q. 11): "Ad primam quaestionem dicendum quod universale est in re ut in subiecto, quia illam denominat, non intellectum. Sed in intellectu est ut in efficiente et ut cognitum in cognoscente" (SCOTUS 1998, p. 826).
} 
tum consideratum ${ }^{6}$.

Uma vez feita este aceno a respeito da diferenciação entre o ente real, por um lado, e o ente lógico ou de razão, por outro lado, voltemos agora, ao modo como Heidegger introduz a discussão a respeito das significações.

\section{DA EXPRESSÃO: SEU MODO DE SER OU ESTATUTO}

O sentido e as significações são formações (Gebilde), segundo uma terminologia usada por Lotze e adotada também por Heidegger. Característico destas formações, diz Heidegger, é o fato de que elas se prendem a palavras e complexos de palavras: "sentido e significações são passíveis de expressão (ausdrückbar) através de formações linguísticas" (HEIDEGGER 1978, p. 290).

As expressões são formas linguísticas (Sprachgestalten) dotadas de significações e de sentido. Sentidos e significações que são pensados vêm à expressão. Eles são exprimíveis através de formações linguísticas (sprachliche Gebilde). Uma coisa é a forma linguística da expressão, o complexo gráfico ou fônico, ou, como dizem os medievais, as voces (vozes) (Cfr. HEIDEGGER 1978, p. 290-291). Outra coisa é o conteúdo da expressão, a significação, o sentido no juízo e no entrelaçamento de juízos (conclusão, silogismo). $\bigcirc$ conteúdo é um "significatum" que está intencionalmente "in men$t^{\text {"7 }}$.

\footnotetext{
${ }^{6}$ Cfr. Quaestiones Quodlibetales (Q. III, Art. 1, n. 8): "Ens ergo vel res isto primo modo accipitur omnino communisse, ex extendit se ad quodcumque quod non includit contradictionem, sive sit ens rationis, hoc est praecise habens esse in intellectu considerante, sive sit ens reale, habens aliquam entitatem extra considerationem intellectus" (SCOTUS 1968, p. 93).

${ }^{7}$ Cfr. Quaestiones super Praedicamenta (Q. 1, n. 12): "Ad quaestionem dici potest quod iste liber non est de decem vocibus ut de primo subiecto - nec aliqua pars logicae est de voce, quia omnes passiones syllogismi et omnium partium eius possunt sibi inesse secundum esse quod habent in mente etsi non proferantur (...), sed est de aliquo priore, quod respectu voces significativae tanCont.
} 
A voz se torna expressão à medida que é dotada de significações e de sentido. Assim, diz Heidegger, a proposição, enquanto sequência de palavras, é singular. Mas o conteúdo da proposição, o juízo, ora é singular, se o predicado é dito de um só, ou universal, se o predicado é dito de muitos. A proposição, como uma sequência de palavras, não é verdadeira ou falsa. Ela é ou não é. É falada ou escrita. Mas não é verdadeira ou falsa. $\mathrm{O}$ sentido da proposição, o juízo, é que é verdadeiro ou falso, não, porém, enquanto simples conteúdo da proposição, mas só à medida que ele tem um valor objetivável, um valor de conhecimento objetivo (HEIDEGGER 1978, p. 292) ${ }^{8}$. Proposição e sentido, palavra e significação pertencem a âmbitos de realidade diversos. Os elementos linguísticos que constituem proposição e palavra são sensivelmente perceptíveis (são acústicos, visuais, motores), são reais e temporais. Já as significações e o sentido se subtraem a uma percepção sensorial e são atemporais. $\mathrm{O}$ elemento linguístico de uma expressão é um signum ad placitum, um signo instituído conforme o agrado ou o arbítrio de quem o usa (HEIDEGGER 1978, p. 293-294) 9 . As significações e os sentidos, porém, se subtraem ao arbítrio daquele que pensa, por ter a sua própria necessidade ideal ou objetiva .

A forma linguística é signo da significação, que, por sua vez, é signo de algo de objetual, de alguma objetualidade (objetos, estados-de-coisas, notas distintivas, formas reais ou

\footnotetext{
tum habet rationem significati” (SCOTUS 1998, p. 652).

${ }^{8}$ Cfr. Quaestiones super Praedicamenta (Q. 1, n. 22): "Similiter, 'significare verum vel falsum' convenit enuntiationi, sed non ut vox est significans conceptum, sed ut conceptus significat rem" (SCOTUS 1998, p. 653).

${ }^{9}$ Cfr. Quaestiones super I et II Perihermeneias (Q. s. I, 4, n. 14): “... et instrumenta naturalia formandi vocem potest homo aliqua imponere, quae sunt signa ad placitum, et non naturalia sive conceptus" (SCOTUS 1998, p. 919).
} 
categoriais). Trata-se do triângulo semiótico que constitui a base da consideração sobre a linguagem em toda a tradição ocidental, e que vem de Aristóteles. No início do tratado, posteriormente intitulado Peri hermeneias ou De interpretatione (16a 3-8) Aristóteles diz o seguinte:

Há os sons pronunciados que são símbolos das afecções na alma, e as coisas que se escrevem que são os símbolos dos sons pronunciados. E, para comparar, nem a escrita é a mesma para todos, nem os sons pronunciados são os mesmos, embora sejam as afecções da alma - das quais esses são os sinais primeiros - idênticos para todos, e também são precisamente idênticos os objetos de que essas afecções são as imagens (ARISTÓTELES 2013, p. 3).

Temos, assim, uma estruturação que se sustenta num mostrar. As letras (ta graphomena) mostram as vozes (ta en te phone). As vozes mostram as disposições na alma (ta en te psyche pathemata). As disposições na alma mostram as coisas (pragmata) que lhe concernem. Duns Scotus questiona sobre a distinção de litteras et voces (letras e vozes), de um lado, passiones (disposições da alma) e res (coisa), de outro lado, na quarta das questões sobre o primeiro livro do "Perì hermeneias" e conclui pela sua conveniência. As disposições da alma (significação e sentido) são as mesmas em todos, bem como as coisas que elas significam, enquanto as letras e vozes são diferentes, dependendo da língua. Com outras palavras, as letras e vozes, que são diferentes de língua para língua, são sinais instituídos pelo arbítrio humano, que representam as disposições da alma (no caso, significação e sentido), que, por sua vez são sinais naturais representativos das coisas $^{10}$.

\footnotetext{
${ }^{10}$ Cfr. Quaestiones in I et II Perihermeneias (Q. s. I, 4, n. 7): "Ad quaestionem dicendum, quod differentia est conveniens; quia passiones, inquanto sunt signa, et res, inquanto sunt significata, sunt eandem apud omnes, nam eadem passio in anima apud quoscumque concipientes repraesentat Cont. 
Para Duns Scotus, palavra e proposição, enquanto formações linguísticas dotadas de significação e de sentido apontam para a esfera objetual. A formação linguística é sinal da significação e do sentido, que é, por sua vez, sinal do objeto. Enfim, palavra e proposição são sinais das coisas. "Quidquid est signum signi, est signum signati" - o que quer que seja sinal do sinal é sinal do assinalado". Assim, palavra e proposição se tornam sinais das objetualidades às quais se referem. No entendimento de Duns Scotus, o conceito é o que é designado imediatamente, o objeto é o que é designado mediatamente pela expressão. $\mathrm{O}$ doutor sutil esclarece que significare é dare intelligere, dar a compreender ${ }^{12}$. O signo é algo de relacional, possui um caráter ou uma função remissiva. $\mathrm{O}$ signo, graças a sua função remissiva, é o fundamento material de que parte o conhecimento do designado. A expressão linguística, porém, não é somente um signo que remete ou se refere a algo. Ele é um signo que significa algo, ou seja, que dá a compreender algo ou algo de algo e que, ademais, se refere a objetualidades, visando dizer, ou seja, mostrar o que se mostra e como se mostra. Assim, para Husserl, a expressão, que funde numa unidade a manifestação sensível, a significação e a referência ao objeto, está ordenada tanto a um valor de conhecimento quanto a um valor de verdade (cfr. SCHÉRER 1969, p.

eamdem rem, quia eadem similitudo in anima semper est eiusdem repraesentativa, sicut est similitudo sensibilis in sensu litterae, et voces in se eaedem, non sunt eaedem apud omnes, inquanto sunt signa, quia nec eadem littera apud omnes repraesentat eamdem vocem, sed vel aliam, vel nullam; nec eadem vox apud omnes significat eamdem passionem, sed vel aliam, vel nullam" (SCOTUS 1998, p. 918).

${ }^{11}$ Cfr. Quaestiones super Praedicamenta (Q. 28, n. 28): “'Quidquid est signum signi, est signum signati', ita quod signum intermedium non varietur in comparatione ad primum signum et ultimum signatum" (SCOTUS 1998, p. 751).

${ }^{12}$ Cfr. Quaestiones super Praedicamenta (Q. 8, n. 1): "Quia significare est intellectum constituere" (SCOTUS 1998, p. 679). 
158). À expressão corresponde ter uma significação; na significação se constitui uma relação com o objeto. Tríplice é o conteúdo de uma expressão: a significação, a referência ao objeto, e, por fim, o preenchimento de sentido. A expressão, pela significação e pela referência ao objeto, dá a compreender alguma coisa acerca de algo. $\mathrm{O}$ preenchimento da intenção signitiva vazia, no modo da confirmação, da documentação intuitiva, leva, por sua vez, à experiência da verdade .

Para Husserl, expressões são signos significativos, distintos dos signos indicativos. Numa descrição fenomenológica da expressão dotada de sentido se podem evidenciar três momentos, que, no entanto, formam uma unidade intimamente fundida: a aparição física da expressão, o ato doador de sentido e o ato preenchedor de sentido. Assim, palavras e proposições são sons articulados animados de sentido. Às expressões são essenciais os atos que conferem a significação, respectivamente, as intenções de significação. A estes atos se acrescentam, de modo extra-essencial, os atos que preenchem as significações, confirmando, reforçando, ilustrando as intenções de significação (cfr. HUSSERL 2012, p. 31-32). Para que o signo se torne expressão é preciso que lhe seja imposto uma significação. Husserl fala de emprestar significação, de conferir sentido. Expressões são unidades de signos e designados (sinais e assinalados) de espécie bem peculiar. Expressões são sinais significativos. A significação adere ao ato significativo. Com a expressão, que suscita o ato que confere o sentido, nos orientamos ao objeto. $\grave{A}$ expressão compete ter uma significação; na significação é que se constitui a relação com o objeto. "Toda e qualquer expressão não quer apenas dizer qualquer coisa, mas também diz algo acerca de qualquer coisa; ela não tem apenas a sua 
significação, mas refere-se também a quaisquer objetos" (HUSSERL 2012, p. 38 - grifo de Husserl). Assim, significação e referência objetiva se distinguem. Expressões podem ter a mesma significação, mas objetos diferentes, por um lado, e, por outro, podem ter significações diferentes, mas o mesmo objeto. Assim, considerando dois enunciados: "este sendeiro é um cavalo" e "Bucéfalo é um cavalo", a expressão um cavalo tem a mesma significação, mas os objetos são diferentes. Por sua vez, dois nomes podem significar coisas diferentes, mas nomear o mesmo, como no exemplo: "O vencedor de Iena - O vencido de Waterloo" (HUSSERL 2012, p. 39). Significação e referência objetiva, no entanto, estão em íntima conexão. A expressão se refere ao objeto por meio da significação. Uma expressão adquire um referimento ao objeto pelo simples fato de que esta significa algo. Por isso é que dizemos que uma expressão designa ou denomina algo por meio do seu significado, ou seja, o ato de significar é o modo determinado de intencionar o objeto em questão, só que justamente este modo de intencionar, e, portanto, o significado mesmo, pode variar enquanto permanece idêntica a direção para o objeto. Se considerarmos, pois, os três momentos que se fundem numa unidade na expressão temos aquilo que, de modo equívoco, se chama o expressado da expressão. "Os termos em relação - manifestação, significação e objeto - pertencem essencialmente a toda e qualquer expressão. Em cada uma, qualquer coisa é manifestada, qualquer coisa é significada e qualquer coisa é nomeada ou de algum modo designada. E, no discurso equívoco, tudo isto se diz 'expresso"” (HUSSERL 2012, p. 41 - grifo de Husserl).

Heidegger (1978, p. 299-301) indica que a expressão resultante de um ato nominal representa o objeto no seu $o$ 
que é, ou seja, na sua essência ou quididade, não na sua existência ou modo de realidade efetiva. Ela não enuncia, apenas representa. Somente com o ato de juízo é que o objeto se torna sujeito da predicação e que dele se pode enunciar algo, algum predicado. Também é pelo ato de juízo que se pode formular uma proposição existencial, ou seja, dizer que algo existe. $\mathrm{O}$ ato de nomear, o ato de julgar, o ato de concluir, são atos que emprestam significado, atos que conferem sentido às expressões. Em sua intencionalidade, estes atos visam à significação da expressão e sua referência ao objeto, e não à própria expressão como tal e em si mesma. Isto quer dizer: enquanto vivemos nestes atos, o nosso interesse nos põe junto daquilo que eles expressam e nomeiam, enunciam e concluem e não junto das expressões ou destes atos em si mesmos.

\section{ENTRELAÇAMENTO DA ANÁLISE INTENCIONAL DA} EXPRESSÃO COM A DOUTRINA DOS MODOS DE SIGNIFICAR, DE INTELIGIR E DE SER DA GRAMMATICA SPECULATIVA

A Grammatica Speculativa não se preocupa com uma explicação genético-factual da linguagem. Sua perspectiva é a de uma compreensão teleológico-essencial de sua natureza e de sua atuação. Seu foco é o fim, a meta, do desempenho linguístico, que consiste na completa comunicação de sentido do discurso. Por meio desta comunicação de sentido, graças à função de conhecimento da linguagem, baseada na referência às objetualidades própria das expressões, pode-se alcançar um saber atual sobre objetualidades. Assim, objetos e estados-de-coisas, notas distintivas e formas reais ou categoriais são trazidas à apresentação. Para que o desempenho da linguagem seja perfeito é preciso que o falante tenha a 
intenção de comunicar o sentido por meio do discurso e que o ouvinte compreenda este sentido (HEIDEGGER 1978, p. 305). No modo de dizer da Grammatica Speculativa: "o sinal da perfeição da construção é gerar o perfeito sentido no espírito de quem ouve" (SCOTUS 1902, p. 183) ${ }^{13}$.

O sentido de um juízo se dá a partir das significações que o compõem e a partir das quais ele se constrói (daí a citação anterior falar de construção). As significações são componentes elementares do juízo. Todo o juízo se constrói a partir de significações. A Grammatica Speculativa ressalta que o intellectus atribui às voces dupla ratio. Dito no modo da fenomenologia: a consciência confere significações e sentido à expressão em dupla perspectiva. A primeira perspectiva é a do significar e é denominada de ratio significandi. Formalmente, a ela corresponde a dictio, a dicção, quer no sentido de manifestação da vida de quem fala, quer no sentido de oratio (oração, elocução). Pela razão do significar a voz se torna expressão, ou melhor, oração ou asserção que significa algo, que dá a compreender algo, e que tem um sentido completo, uma sententia. A segunda perspectiva é a do cosignificar e é denominada de ratio cosignificandi. Formalmente, a ela corresponde a pars orationis, a parte da oração, que significa, dá a compreender algo, de modo incompleto e dependente, apenas em conexão com outras partes. A quarta das Investigações Lógicas de Husserl discute problemas relacionados com isso, ao tratar da diferença entre signifi-

\footnotetext{
${ }^{13}$ Grammatica Speculativa (C. LIV, n. 227): "Ex his patet, quod signum perfectionis constructionis est generare perfectum sensum in animo auditoris". Embora tenha se revelado a inautenticidade da "Grammatica Speculativa" enquanto obra de Duns Scotus, vamos cita-la segundo a edição de 1902, feita pelo P. Fr. Mariano Fernandez Garcia, que ainda a atribuía ao Doutor Sutil. Este problema da autenticidade deste opúsculo não incide sobre o conteúdo do pensamento aqui exposto. Como já dissemos, M. Grabmann, o atribuiu a Tomás de Erfurt. Nas citações deste opúsculo, serão respeitados os grifos do editor.
} 
cações independentes e dependentes. As palavras são partes da oração ${ }^{14}$. $O$ estudo da forma de significar de cada tipo ou espécie de palavra pertence à morfologia da gramática especulativa .

Para Duns Scotus, duplo é o modus significandi: um activus" e um passiuus ${ }^{15}$. O modo de significar ativo é apresentado por Heidegger como um empenho (Leistung) da consciência, como ato desta. $\mathrm{O}$ modo passivo é apresentado como o desempenho, o resultado deste ato. $\mathrm{O}$ modo ativo seria o lado subjetivo e o modo passivo o lado objetivo da significação. Neste ponto, Heidegger retoma as considerações de Husserl sobre o significar e a significação, ou seja, em terminologia fenomenológica, sobre o aspecto noético e o noemático da significação. Ele recorre ao $\$ 124$ de Ideias I, que diz: "No aspecto noético, a designação 'exprimir' indica uma camada particular de ato, ao qual todos os demais atos, cada um a seu jeito, devem ser ajustados e a ele fundidos de uma maneira digna de atenção, isto é, de modo que todo sentido de ato noemático e, consequentemente, a referência nele contida à objetividade seja marcada 'conceitualmente' no noemático da expressão" (HUSSERL 2006, p. 277). Ao trazer esta citação Heidegger relaciona a objetuali-

\footnotetext{
${ }^{14}$ Grammatica Speculativa (C. I, n. 4): "Iuxta quod notandum, quod cum intellectus vocem ad significandum, et cosignificandum imponit, duplicem ei rationem tribuit, scilicet, rationem significandi, quae vocatur significatio, per quam efficitur signum, vel significans; et sic formaliter est dictio; et rationem consignificandi, quae vocatur Modus significandi activus, per quam vox significans fit consignum, vel consignificans; et sic formaliter est pars orationis" (SCOTUS 1902, p. 8-10).

${ }^{15}$ Grammatica Speculativa (C. I, n. 3): "Circa primum est sciendum, quod modus significandi duo importat aequivoce. Dicitur enim de modo significandi activo et passivo. Modus significandi activus est modus, sive proprietas vocis, ab intellectu sibi concessa, mediante qua, vox proprietatem rei significat. - Modus significandi passivus est modus, sive proprietas rei, proutest per vocem significata. Et quia significare et cosignificare est quodammodo agere, et significari et consignificari est quodammodo pati, inde est, quod modus vel proprietas vocis, mediante qua vox proprietatem rei active significat, modus significandi activus nominatur; modus vero, vel proprietas rei, prout per voces passive significatur, modus significandi passivus nuncupatur" (SCOTUS 1902, p. 7-8).
} 
dade a que se referem as expressões com o modus essendi, o sentido noemático do ato de exprimir com o modus significandi passivus e o sentido noético do mesmo com o modus significandi actiuus (HEIDEGGER 1978, p. 309-310) .

As significações são formações. Significações são formadas a partir do e no ato mesmo de significar. $O$ princípio de diferenciação das formas da significação origina-se nos atos intencionais. Tratam-se, neste caso, de atos que conferem ou emprestam significação e doam sentido às palavras. A Grammatica Speculativa formula uma lei fundamental: "intellectus ad actum determinatum non vadit nisi aliunde determinetur" - o intelecto não passa a ser um ato determinado a não ser que seja determinado desde algum lugar (SCOTUS 1902, p. 11). Isso quer dizer: a intelecção deve originar de algo para conferir significação e doar sentido às palavras e orações. Esta origem a partir da qual o intelecto atua os seus atos de dar significação e sentido é a proprietas rei, a propriedade da coisa. Os atos doadores de significação e de sentido são atos intencionais. Estes trazem consigo uma referência a objetualidades. A proprietas rei, que tem, cada vez, um modus essendi, é a dimensão das objetualidades, determinante da expressão à medida que esta surge para se referir a isto e a aquilo que está sendo desta ou daquela maneira. Os atos intencionais, por sua vez, têm qualidade e matéria. A qualidade é a forma do desempenho do ato de dar significação e sentido, é a forma da nóesis deste ato, o modus significandi actiuus. A matéria é o conteúdo significativo correlato do ato de dar significação e sentido, é o sentido noemático, o modus significandi passivus. Nas Investigações Lógicas resulta que a matéria do ato é o seu sentido apreensional do objeto (cfr. HUSSERL 2014, p. 353-357). Ela faz o ato ter este objeto e não outro, ou melhor, ela faz o ato ter este 
objeto dado deste modo, apreendido desta maneira e não de outra. A matéria (Materie) é, pois, o sentido da apreensão ou compreensão objetual (Sinn der gegenständlichen Auffassung) ou, simplesmente, o sentido apreensional (Auffassungssinn) de um ato. O objeto intencional nunca é apreendido de modo absoluto, mas, sempre, se dando deste ou daquele modo a este ou aquele tipo de ato intencional. $\mathrm{O}$ modo de autodatidade do objeto intencional constitui o sentido no qual este objeto é apreendido. Um mesmo objeto pode se dar em um mesmo tipo de ato através de sentidos diferentes. A tais sentidos correspondem diferentes matérias intencionais (HEIDEGGER 1978, p. 311).

O modus significandi está em correspondência com o modus intelligendi e com o modus essendi. O modus intelligendi é a ratio concipiendi, o modo e a maneira na qual alguém apreende algo objetivamente e sabe disso. O modus essendi só pode entrar na função diferenciadora da significação, à medida que ele é dado de modo cognitivo, ou seja, à medida que ele é apreendido pelo intelecto. A coisa, ou melhor, a propriedade da coisa, é apreendida pelo intelecto. Não a coisa enquanto realidade própria entra na intelecção, ou vem à compreensão, mas a sua significância, o seu modo de ser, que se apresenta como forma, como species intelligibilis. Uma expressão dá a compreender algo e, ao mesmo tempo, se refere a algo. Este algo ao qual ela se refere não é o objeto em si, mas o objeto enquanto conhecido (HEIDEGGER 1978, p. 316) .

O modus intelligendi pode também ser activus ou passivus $^{16}$. O modus intelligendi activus é o modo da atuação da ob-

\footnotetext{
${ }^{16}$ Cfr. Grammatica Speculativa (C. III, n. 10): "Circa tertium notandum, quod modi significandi activi immediate a modis intelligendi passivis sumuntur. Iuxta quod sciendum est, quod, sicut Cont. 
jetivação da proprietas rei e de seu modus essendi. O modus intelligendi passivus é o modus essendi enquanto objetivado. Este, por sua vez, determina as formas das significações.

Os modos de ser, de inteligir e de significar se fundem na constituição da expressão. O modo de ser, o modo de inteligir passivo e o modo de significar passivo são material e realmente o mesmo, a mesma matéria de objetivação (Cfr. HEIDEGGER 1978, p. 317) ${ }^{17}$. Apenas se diferenciam formalmente, isto é, na perspectiva, respectivamente, do ser, do inteligir e do significar. $\mathrm{O}$ modo de ser é a realidade em sua objetualidade, é o que é dado e sua datidade. $\mathrm{O}$ modo de inteligir passivo é o modo de ser, a realidade, que entrou na esfera do conhecimento. $\mathrm{O}$ modo de significar passivo é o modo de ser, a realidade, que, uma vez conhecida ou inteligida, entrou na significação. As coisas, assim, se manifestam, tornam-se conhecidas em sua significância (Bedeutsamkeit) e vêm à significação (Bedeuntung), e, por fim, recebem uma expressão por meio de uma forma linguística .

Os modos de inteligir ativo e de significar ativo se diferenciam material e formalmente (cfr. HEIDEGGER 1978, p. 319). Pertencem a diferentes regiões de essência. $O$ modo de inteligir ativo é dado pela consciência e por seus atos cognitivos, que se referem às objetualidades, tornando-as apreendidas, conhecidas. $\mathrm{O}$ modo de significar ativo é dado pela consciência e por seus atos de doar significação e sentido à expressão.

\footnotetext{
duplex est modus significandi, scilicet activus et passivus, ita duplex est modus intelligendi, scilicet activus et passivus. Modus intelligendi activus est ratio concipiendi, qua mediante, intellectus rei proprietates significat, concipit vel apprehendit. - Modus autem intelligendi passivus est proprietas rei, prout ab intellectu apprehensa".

${ }^{17}$ Cfr. Grammatica Speculativa (C. IV, n. 12): "Circa quartum, notandum, quod modi essendi, et modi intelligendi passivi, et modi significandi passivi, sunt idem materialiter et realiter, sed differunt formaliter" (SCOTUS 1902, p. 15-16).
} 
O modo de significar passivo materialmente está na coisa (in subjecto) e formalmente está no intelecto ${ }^{18}$. $\mathrm{O}$ modo de significar ativo, materialmente está na vox significativa e formalmente está no intellectus. A propriedade da coisa é a causa eficiente remota da significação. $O$ intelecto é a causa eficiente próxima da significação ${ }^{19}$ (HEIDEGGER 1978, p. 320-321).

Estamos, pois, diante de uma construção lógica e de suas peças (Lotze). A Grammatica Speculativa mesma entende a concatenação dos modi significandi teleologicamente, a partir de uma constructio, construção. Ela aplica a teoria dos quatro princípios ou causas a esta construção (HEIDEGGER 1978, p. 321).

Os princípios materiais (constructibilia) desta construção são as significações individuais como elementos de uma conexão significativa. Existem significações determinantes e significações dependentes. Como aludido, a quarta das Investigações Lógicas de Husserl trata desta distinção, que também está presente na Grammatica Speculativa .

Consideramos oportuno fazer, aqui, uma alusão ao conteúdo da quarta das Investigações Lógicas, que trata da ideia de uma gramática pura. Esta investigação prolonga a anterior, que trata de elementos para uma doutrina do todo e das partes, aplicando, contudo, os seus resultados no

\footnotetext{
${ }^{18}$ Cfr. Grammatica Speculativa (C. V, n. 16): "Circa quintum est notandum quod modus significandi passivus materialiter est in re, ut in subiecto; quia materialiter est proprietas rei; rei autem proprietas est in eo, cuius est, ut in subiecto. Formaliter autem est in eo subiecto, in quo est modus significandi activus, quia formaliter a modo significandi activo non discrepat" (SCOTUS 1902, p. 19).

${ }^{19}$ Cfr. Grammatica Speculativa (C. V, n. 17): "Modus autem significandi activus, cum sit proprietas vocis significativae, materialiter est in você significativa, ut in subiecto; in proprietate autem rei sicut causatum in causa efficienti radicali et remota; et in intellectu sicut causatum in causa eficiente próxima; et in constructione ut causa efficiens in suo effectu proprio" (SCOTUS 1902, p. 19).
} 
campo dos problemas referentes ao significado ${ }^{20}$. Por outro lado, dá um passo adiante através do tratamento de problemas relacionados a uma gramática pura. Como o nome "gramática pura" está a indicar, não se trata de realizar discussões gramaticais empíricas, que se refiram a uma língua qualquer historicamente determinada, mas de discussões que vão ao cerne do nexo entre pensamento e linguagem e que tentam trazer à tona leis lógico-gramaticais puras. Para além da realização de uma morfologia pura dos significados, trata-se de empreender uma teoria pura da validade dos significados que pressupõe aquela. A análise fenomenológica da linguagem deve lidar antes de tudo com representações, precisamente com representações expressivas. Mas a expressão articula sempre distinções lógicas que se mantém intimamente relacionadas com as distinções gramaticais operadas no interior de uma língua, graças a um paralelismo entre pensamento e palavra.

Dado que, em consequência do fato de que as distinções verbais e as do pensamento andam, grosso modo, a par umas das outras, e também sobretudo as formas verbais e as formas de pensamento, existe uma tendência natural para procurar uma diferença lógica sob toda e qualquer diferença gramaticalmente cunhada, seria, então, um importante assunto lógico levar à clareza analítica a relação de expressão com significação e, no retorno do significar vago até o

\footnotetext{
${ }^{20} \mathrm{Na}$ terceira das Investigações Lógicas Husserl faz a distinção entre conteúdos autônomos (selbstängigen) e não autônomos (unselbständigen). Esta distinção, que foi apresentada por Stumpf, mas que remonta à discussão entre Berkeley e Locke, depende da não separabilidade, no caso dos conteúdos autônomos, ou da separabilidade, no caso dos conteúdos não autônomos, das partes que eventualmente os compõem. Conteúdos não autônomos correspondem aos conceitos concretos, são compostos e, por conseguinte, separáveis nas suas partes. Os conteúdos autônomos, ao invés, correspondem aos conceitos abstratos, isto é, formais, são simples e, por conseguinte, inteiros, sem partes a serem separadas. No caso de um conceito concreto, por exemplo, de um "cavalo", eu posso imaginá-lo na composição de suas partes e, na imaginação, separar as suas partes, como por exemplo, a cabeça do corpo, as orelhas da cabeça, etc. No caso de um conceito abstrato, porém, não é possível fazer uma separação do gênero; assim, se eu concebo a ideia de "movimento", não me é possível pensar esta ideia sem pensar ao mesmo tempo um corpo que se move.
} 
correspondente significar articulado, claro, saturado da plenitude das intuições exemplificadoras e que, por esta via, se preenche, reconhecer o meio pelo qual deve ser decidida, em cada caso dado, a questão de saber se uma distinção deve valer como lógica ou como meramente gramatical (HUSSERL 2014, p. 12).

Não se trata, pois, aqui de querer reduzir a análise do pensamento à análise do funcionamento gramatical da linguagem. Na verdade, as línguas não expressam com igual intensidade de decisão as diferenças de significado essenciais e as acidentais. Nem sempre diferenças gramaticais implicam diferenças lógicas .

Só uma completa clarificação das relações fenomenológicas de essência entre expressão, significação, intenção de significação e preenchimento de significação pode fornecer-nos, aqui, a posição intermédia segura e emprestar toda a distinção exigível à relação entre análise lógica e análise gramatical (HUSSERL 2014, p. 12-13) .

$\mathrm{Na}$ quarta investigação lógica, de um modo especial, é tratado o problema das significações independentes e dependentes. Existem expressões categoremáticas e sincategoremáticas, completas e incompletas. Expressões categoremáticas têm significação por si mesmas. Já as sincategoremáticas não têm significação por si mesmas, mas são apenas co-significantes (exemplos: e, ou, por). Correspondentemente, há também significações categoremáticas e sincategoremáticas, ou, mais exatamente, significações independentes e dependentes (cfr. HUSSERL 2014, p. 261). As significações dependentes carecem de complemento, ou seja, carecem de serem unidas a outras significações, para formar um significado completo independente. A Grammatica Speculativa, de modo símile, distingue entre os elementos de uma oração, pondo em relevo os que são determinantes e os que são dependentes. Assim, por exem- 
plo, na oração homo albus corrit bene o nome substantivo homo e o verbo corrit são determinantes. $\mathrm{O}$ nome adjetivo albus e o advérbio bene são dependentes, isto é, dependem das significações determinantes .

Vimos, pois, que os princípios materiais (constructibilia) da construção do juízo são as significações individuais como elementos de uma conexão significativa. O princípio formal da construção é a unificação dos elementos, isto é, as significações individuais. Forma é o que dá o ser a alguma coisa. A construção só acontece como unificação de elementos. $\mathrm{O}$ princípio eficiente pode ser intrínseco ou extrínseco. Intrínsecos são os modos de significar. Extrínsecos são os modos de inteligir. O princípio final é o expressar aquilo que é dado na consciência, ou seja, é a expressão do conceito que está na mente (HEIDEGGER 1978, p. 323-327) .

A construção tem suas leis. Ela precisa tornar-se uma constructio debita. Ela precisa obedecer a uma certa congruitas. Daqui vem a ideia de uma Gramática a priori. Para Husserl, a ideia de uma gramática a priori corresponde às leis apriorísticas formais que regem a união das significações (HEIDEGGER 1978, p. 328). Destas leis a priori das significações na estruturação do discurso trata também a quarta das Investigações Lógicas. No $§ 10$ desta Husserl fala de "um dos fatos mais fundamentais do domínio das significações, a saber, que as significações estão sob leis apriorísticas que regulam a sua conexão em novas significações" (cfr. HUSSERL 2014, p. 270 - grifo de Husserl). A possibilidade ou impossibilidade de conectar significações dependem dos gêneros sob os quais elas caem, ou seja, das categorias de significação. Por exemplo, a expressão "esta árvore é verde" é uma expressão unitariamente significativa. Sua forma proposicional, formalizando, é "este S é p". Aqui estão uni- 
das uma matéria nominal com uma matéria adjetiva. As variantes $S$ e $p$ podem ser substituídas por outras significações, desde que estas também caiam sob a categoria de matéria nominal (S) e de matéria adjetiva (p) reunidas na forma proposicional "s é p". A permuta das matérias deixa de acontecer assim que as categorias são transgredidas. Assim, palavras postas umas ao lado das outras nem sempre resultam num sentido unitariamente completo. Exemplos: "esta ligeireza de expressão é verde; mais intenso é redondo; esta casa é igual" (cfr. HUSSERL 2014, p. 273). Cada uma das palavras tem sentido, mas o ajuntamento delas não forma uma conexão plena de sentido .

Heidegger recorda que forma linguística, significação e direção de preenchimento da intenção de significação são um todo. O modo de significar tem um valor sintático, ou seja, ele segue determinados principios de ordenação das significações. O modo de inteligir tem um valor de verdade que só se expressa no juizo (HEIDEGGER 1978, p. 337). A doutrina da significação se torna, então, uma região parcial da lógica. A lógica é a teoria do sentido teorético como tal. Ela é doutrina dos elementos de sentido, ou seja, doutrina da significação; doutrina da estrutura de sentido, ou seja, doutrina do juizo; e, por fim, doutrina das diferenciações das estruturas de sentido e de suas formas sistemáticas, ou seja, doutrina da ciência (HEIDEGGER 1978, p. 337).

\section{CONCLUSÃO}

Desta exposição se podem haurir diversas correspondências entre a teoria da significação de Husserl e a doutrina da significação de Duns Scotus e da Grammatica Speculativa. Em síntese: 
1) A distinção o ente lógico ou ens rationis e o ente real: o que afasta a possibilidade de uma compreensão psicologista da lógica.

2) A tríade manifestação (litterae, voces), significação (passiones animae) e objeto (res) como estruturação essencial de toda expressão.

3) $\bigcirc$ estatuto intencional da significação: esta é um conteúdo pensado, que está na mente, ou seja, que está intencionalmente in intellectu, sendo que "intencionalmente" significa obiective (como o que representado) e não subiective (como o que é parte real da mente).

4) $\bigcirc$ sentido teleológico da linguagem: visa gerar o sentido e dar a compreender, por um lado, e, por outro, visa a verdade, a partir do preenchimento do mesmo sentido.

5) $\mathrm{O}$ ato de conferir sentido tem dupla perspectiva ( $r a$ tio): a de significar e a de co-significar; daí deriva a distinção das partes da oração em expressões categoremáticas e sincategoremáticas, e, por conseguinte, possibilita falar de significações independentes e significações dependentes .

6) $O$ modo de significar ativo corresponde ao sentido noético do ato de conferir sentido. $O$ modo de significar passivo corresponde ao sentido noemático da expressão .

7) $\bigcirc$ modo de inteligir ativo corresponde ao empenho da consciência nos seus atos cognitivos. $\mathrm{O}$ modo de inteligir passivo corresponde à objetualidade que, como significância (species intelligibilis) entra na esfera do conhecimento.

8) $\bigcirc$ modo de ser é a objetualidade em sua autodati- 
dade e em seu caráter de ser apreendido: o fenômeno em sentido originário.

9) A Grammatica Speculativa como exemplo de uma tentativa já realizada de uma Gramática Pura que as Investigações Lógicas se propunham como uma tarefa para o porvir .

Cada um dos pontos desta conclusão, no entanto, antes que considerações finais, são pontos de partida para ulteriores investigações, a serem desenvolvidas, tanto no sentido de um aprofundamento, quanto no sentido de uma mais ampla problematização, que não cabem no limite deste artigo.

Seja para Duns Scotus, seja para Husserl, seja para Heidegger, o que está em questão não é tanto explicar a linguagem desde um ponto de vista genético-factual, mas compreender a linguagem desde um ponto de vista teleológico-essencial. Eles buscam haurir, sacar para fora, os últimos fundamentos teoréticos, que jazem na linguagem. São diversos caminhos de pensamento que se dialogam nesta tentativa de compreensão. A teoria da significação significa, neste caso, um cruzamento destes diversos caminhos, que merecem ser aprofundados em ulteriores investigações.

Abstract: This article aims to expose and comment on the theory of meaning presented by Heidegger in his "habilitation dissertation" (FREIBURG 1915) on the Grammatica Speculativa in that time attributed to Duns Scotus. Heidegger, in his interpretation, interweaves elements of the theory of meaning present in Husserl and Duns Scotus. The doctrine of modes of meaning, of understanding and of being, of the Grammatica Speculativa, is read since an intentional phenomenological analysis. This article tries to expose this interlacement, point out the correspondences between the Husserl's theory of meaning and the doctrine of the modes of meaning, of understanding and of being, in the Grammatica Speculativa.

Keywords: Logic being; meaning; intentionality; modes of meaning, of understanding and of being; Grammatica Speculativa. 


\section{REFERÊNCIAS BIBLIOGRÁFICAS}

ARISTÓTELES. Da Interpretação (Ed. Bilíngue). São Paulo: UNESP, 2013.

HEIDEGGER, M. Frühe Schriften - Gesammtausgabe Band

I. Frankfurt am Main: Vittorio Klostermann, 1978.

HUSSERL, E. Ideias para uma fenomenologia pura e para uma filosofia fenomenológica. Aparecida: Ideias \& Letras, 2006.

- Investigações Lógicas: Investigações para a Fenomenologia e a Teoria do Conhecimento. Rio de Janeiro: Forense, 2012.

. Investigações Lógicas: Prolegômenos à Lógica Pura. Rio de Janeiro: Forense, 2014.

SCHÉRER, R. La fenomenología de las "Investigaciones Lógicas" de Husserl. Madrid: Gredos, 1969.

SCOTUS, J. D. B. Johannes Duns Scoti Doct. Subtilis Grammaticae Speculativae (Cura et editio P. Fr. Mariani Fernandez Garcìa). Ad Claras Acquas (Quaracchi) - Prope Florentiam: Ex Typographia Collegii S. Bonaventurae, 1902.

SCOTUS, J. D. Opera Omnia - editio minor I: Opera Philosophica (a cura di Giovanni Lauriola). Bari: Alberobello, 1998.

SCOTUS, J. D. Cuestiones Cuodlibetales (Obras del Doctor Subtil Juan Duns Escoto). Madrid: Biblioteca de Autores Cristianos, 1968. 